\title{
Ferrocenoyl Piperazide as Derivatizing Agent for the Analysis of Isocyanates and Related Compounds Using Liquid Chromatography/ Electrochemistry/Mass Spectrometry (LC/EC/MS)
}

\author{
Bettina Seiwert, Hartmut Henneken, and Uwe Karst \\ Department of Chemical Analysis and $\mathrm{MESA}^{+}$, Institute for Nanotechnology, University of Twente, \\ Enschede, The Netherlands
}

Ferrocenoyl piperazide is introduced as a new pre-column derivatizing agent for the analysis of various isocyanates in air samples using reversed-phase liquid chromatographic separation, electrochemical oxidation/ionization, and mass spectrometry. The nonpolar derivatives can be separated well using a phenyl-modified stationary phase and a formic acid/ammonium formate buffer of $\mathrm{pH} \mathrm{3}$, which yields excellent separations, especially for one problematic group of isocyanates consisting of 2,4- and 2,6-toluylenediisocyanate (2,4- and 2,6-TDI) and hexamethylenediisocyanate (HDI). Electrochemical oxidation at low potentials $(0.5 \mathrm{~V}$ versus $\mathrm{Pd} / \mathrm{H}_{2}$ ) leads to formation of charged products, which are nebulized in a commercial atmospheric pressure chemical ionization (APCI) source, with the corona discharge operated only at low voltage. Limits of detection between 6 and $20 \mathrm{nmol} / \mathrm{L}$ are obtained for the isocyanate derivatives, and calibration is linear over at least two decades of concentration. The method is applied for the analysis of air after thermal degradation of a polyurethane foam, and it is demonstrated that it is suitable as well for the analysis of carboxylic acid chlorides and of isothiocyanates. (J Am Soc Mass Spectrom 2004, 15, 1727-1736) (c) 2004 American Society for Mass Spectrometry

I socyanates (R-NCO) nowadays find widespread application in the manufacture of pharmaceuticals, - pesticides, and polyurethanes (PUR). Isocyanatebased polymers have found many applications, e.g., as paints, adhesives, insulations, sealants, textile fibers, lacquers, and finishes. The industrial use of isocyanates is mainly based on their high reactivity towards nucleophilic agents, e.g., alcohols or amines, often showing quantitative reaction yields without any side reactions [1]. However, this reactivity causes a high toxicity. When inhaled, isocyanates can bind to human tissues, proteins, and DNA, forming toxic adducts and metabolites which may cause adverse health effects, especially to the respiratory system, including acute pulmonary edema, chronic obstructive pulmonary diseases, and bronchial asthma $[2,3]$.

Occupational exposure can occur at many workplaces while handling the native compounds, during spraying isocyanate-based paints, or when heating and

Published online October 26, 2004

Address reprint requests to Dr. U. Karst, Department of Chemical Analysis and $\mathrm{MESA}^{+}$Institute for Nanotechnology, University of Twente, P.O. Box 217, 7500 AE Enschede, The Netherlands. E-mail: u.karst@utwente.nl processing polyurethane (PUR) or related products [4]. It is known that complex mixtures of isocyanates are set free during these processes. These mixtures also comprise low-molecular monoisocyanates although the PUR material had originally been produced from diisocyanates [5].

In order to comply with the $5 \mathrm{ppb}$ threshold limit value (TLV), identification and sensitive quantification of monoand diisocyanates in workplace air is very important. As the analytes are very reactive, direct spectroscopic methods are not applicable to the analysis of individual isocyanates and derivatization methods must be used. Early methods were based on colorimetric techniques with restricted selectivity and sensitivity [6], while modern analytical approaches focus on derivatization with nucleophilic reagents, followed by liquid chromatographic (LC) separation and photometric or fluorometric detection. In the past decades, compounds containing amine functionalities, such as 1-(2-methoxyphenyl)-piperazine (2-MP) [7-12], 9-(N-methylaminomethyl)-anthracene (MAMA) [13, 14], 1-(9-anthracenyl-methyl)-piperazine (MAP) [15, 16], 1-(2-pyridyl)-piperazine (2-PP) [17], and 4-nitro-7piperazino-benzo-2-oxa-1,3-diazole (NBDPZ) [18] were introduced as derivatizing reagents. In recent years, the 
use of mass spectrometry as a detection technique became more and more important because of its high selectivity and low limits of detection. A sensitive MS method makes use of dibutylamine (DBA) as the derivatizing reagent [4, $5,12,19]$. While DBA is only suited for MS detection because of the lack of chromophoric or fluorophoric groups, other reagents that were previously used with photometric detection are now applied with increased sensitivity in tandem MS detection [20, 21].

Ferrocene-based derivatizing agents have been used in combination with chromatographic separations and selective detectors for a long time. Gas chromatography (GC) of ferroceneboronates of diols and related compounds with electron impact mass spectrometric detection was described by Brooks and Cole [22]. Rolfes and Andersson derivatized phenols with ferrocenecarboxylic acid chloride, separated the derivatives by GC, and used the highly selective atomic emission detector for quantification [23, 24]. The majority of publications on ferrocene-based derivatizing agents, however, describes the use of LC with electrochemical detection [25-33]. Shimada et al. [25] introduced N-substituted ferrocene-containing maleimides for the derivatization of thiols with subsequent LC and dual-electrode coulometric detection. Fatty acids were determined by the same group based on derivatization with a bromoacetylferrocene, LC and electrochemical detection [26]. Similar approaches were introduced for the determination of brassosteroids using ferroceneboronic acid by Gamoh et al. [27], and for amino acids, peptides and proteins by Eckert and Koller [28, 29], Cox et al. [30] and Shimada et al. [31, 32]. Lo et al. recently presented ferrocenehexanethiol for the pre-column derivatization of microcystins [33].

Van Berkel and co-workers introduced the use of the electrospray interface itself as electrochemical reactor after derivatization of various groups of analytes with ferrocenes [34-37]. Electrochemical oxidation of the derivatives leads to formation of the respective ferrocinium ions, which are detected in the mass spectrometer with excellent limits of detection, as demonstrated for the analysis of alcohols in food extracts [34] and plant oils [35]. The fragmentation pathways of the derivatives were elucidated in further work of the same group [36]. Ferroceneboronic acid was used by Van Berkel et al. to analyze alkenes after their oxidation to diols [37], and by Williams et al. to determine several neutral mono- and disaccharides [38] and various estrogens [39]. None of these studies involved a separation. Karst et al. used the combination of pre-column derivatization with ferrocenecarboxylic acid chloride, LC separation, electrochemical conversion, and MS detection for the determination of alcohols and phenols [40]. The method could be combined with rapid separations on very short LC columns [41] and was applied for the analysis of alcohols and phenols in mineral oils [42].

Based on this work, it was proposed to devise a dedicated ferrocene-based method for the analysis of isocyanates with reversed-phase liquid chromatography, electrochemical conversion and mass spectrometry. The respective data are presented in this publication.

\section{Experimental}

\section{Chemicals}

Ferrocenecarboxylic acid, 4-(N,N-dimethylamino)pyridine (DMAP), piperazine, acetyl chloride, most isocyanates, propyl isothiocyanate, formic acid, and ammonium formate were purchased from Aldrich Chemie (Steinheim, Germany) in the highest quality available. Methyl isocyanate was obtained from Chem Service (West Chester, PA).

Water and acetonitrile (HPLC-S gradient grade were purchased from Biosolve (Valkenswaard, The Netherlands).

\section{Instrumentation}

All HPLC-MS experiments were performed on a LCMS QP8000 single quadrupole mass spectrometer equipped with an atmospheric pressure chemical ionization (APCI) source connected to a SCL-10Avp controller unit, DGU-14A degasser, two LC-10 ADvp pumps, SUS mixing chamber $(0.5 \mathrm{~mL})$, SIL-10A autosampler, and a SPD-10AV UV/vis detector. The equipment used for on-line electrochemical oxidation was obtained from ESA (Chelmsford, MA) and comprised a Coulochem II electrochemical detector and a model 5021 conditioning cell. For the protection of the working electrode, a PEEK in-line filter (ESA) was mounted between column and electrode.

\section{LC Conditions}

A binary gradient of acetonitrile and a formic acid/ ammonium formate buffer $(20 \mathrm{mM}, \mathrm{pH}=3)$ was used for the liquid chromatographic separation. The column employed for the MS measurements was a NC-03 Prontosil 120-5-PHENYL (Bischoff chromatography, Leonberg, Germany) with $5 \mu \mathrm{m}$ particle size, $120 \AA$ A pore size, $250 \mathrm{~mm}$ length and $3.0 \mathrm{~mm}$ i.d.; injection volume was $10 \mu \mathrm{L}$. As flow rate, $0.6 \mathrm{~mL} / \mathrm{min}$ was selected. The following gradient profile was selected for all measurements:

$\mathrm{t}$ [min] $0.03 \quad 15232534363739$

$\mathrm{c}\left(\mathrm{CH}_{3} \mathrm{CN}\right)$ [\%] 20505560909020 stop

\section{MS Conditions}

The APCI interface was used as a heated nebulizer. Therefore, an APCI probe voltage of only $0.1 \mathrm{kV}$ was applied. The nebulizer flow rate was set to $2.5 \mathrm{~mL} / \mathrm{min}$, the APCI temperature was set to the highest value possible $\left(500^{\circ} \mathrm{C}\right)$ and the curved desolvation line (CDL) 
temperature to $300{ }^{\circ} \mathrm{C}$. The CDL voltage was set to -5 $\mathrm{V}$, the deflector voltages to $+35 \mathrm{~V}$ and the detector voltage to $1.7 \mathrm{kV}$.

\section{Conditions for Cyclic Voltammograms}

Fc-Pz or the derivatized isocyanates were dissolved in a mixture of $10 \mathrm{ml}$ ammonium formate buffer $(0.1 \mathrm{M})$ and $10 \mathrm{ml}$ acetonitrile to form a 0.32 to $0.37 \mathrm{mM}$ solution. After 5 min of stirring under a nitrogen atmosphere, the stirrer was turned of and cyclic voltammograms were recorded in a potential range from -1000 to $1000 \mathrm{mV}$ with a scan rate of $50 \mathrm{mV} / \mathrm{s}$.

\section{Synthesis of the Derivatizing Agent}

In order to derivatize isocyanates, ferrocenoyl piperazide $(\mathrm{m}=298 \mathrm{Da})$ was synthesized. Ferrocenecarboxylic acid chloride was prepared according to literature $[23,24,40]$ : At room temperature, a solution of $1.43 \mathrm{~mL}$ (16.6 mmol) of oxalyl chloride in $30 \mathrm{~mL}$ of toluene was added to a stirred suspension of $3.0 \mathrm{~g}(13.0 \mathrm{mmol})$ of ferrocene carboxylic acid and catalytic amounts (3.5 $\mathrm{mg}$ ) of DMAP in $35 \mathrm{~mL}$ of toluene. The reaction mixture was stirred for $1 \mathrm{~h}$ at room temperature. The color changed from orange to dark red. The solution was heated for $2 \mathrm{~min}$ to $80^{\circ} \mathrm{C}$ to complete the reaction. After evaporation of the solvent, the residue was extracted several times using warm pentane $\left(\mathrm{T}=30^{\circ} \mathrm{C}\right)$. Ferrocenecarboxylic acid chloride precipitated as dark red cubic crystals and was used without further purification. The yield was $2.65 \mathrm{~g}(82 \%)$. A solution of ferrocene-carboxylic acid chloride $(2.5 \mathrm{~g}, 10 \mathrm{mmol})$ in $60 \mathrm{~mL}$ dry $\mathrm{CH}_{2} \mathrm{Cl}_{2}$ was added dropwise to a solution of piperazine $(3.4 \mathrm{~g}, 40 \mathrm{mmol})$ in $20 \mathrm{~mL}$ dry $\mathrm{CH}_{2} \mathrm{Cl}_{2}$ over a period of half an hour under cooling in an ice bath. Afterwards, it was stirred for $1 \mathrm{~h}$ at room temperature, before a part of the solvent was evaporated and the solution was filtered in order to remove the excess of piperazine. Subsequently, the solution was evaporated to dryness. As a side product, bis(ferrocenoyl)piperazide may be obtained, which is only poorly soluble in ether. Therefore, the crude product was suspended in ether and the solution was filtered and evaporated. The obtained yellow to orange substance was a relatively clean derivatization reagent with only small amounts of side product. Further cleaning of the substance by preparative column liquid chromatography in portions of $500 \mathrm{mg}$ on a stationary phase of silica gel 100 from Fluka (Buchs, Switzerland) with only methanol as eluent yielded $720 \mathrm{mg}(25 \%)$ of pure derivatization reagent.

\section{Synthesis of the Derivatives}

The derivatives of monoisocyanates and isothiocyanates were prepared as follows: An excess of the respective monoisocyanate or isothiocyanate $(0.4 \mathrm{mmol})$ was dissolved in $15 \mathrm{~mL}$ of anhydrous toluene and the derivatizing reagent $(60 \mathrm{mg}, 0.2 \mathrm{mmol})$ in anhydrous toluene $(30 \mathrm{~mL})$ was added. The mixture was stirred at room temperature for $30 \mathrm{~min}$. Afterwards, $2 \mathrm{~mL}$ methanol were added to destroy the remaining isocyanates. The solvent was removed by evaporation. By this method, the derivatives of methyl isocyanate (MIC), ethyl isocyanate (EIC), phenyl isocyanate (PIC), and propyl isothiocyanate were synthesized.

For the synthesis of acetyl-Fc-Pz, $125 \mathrm{mg}(0.42 \mathrm{mmol})$ $\mathrm{Fc}-\mathrm{PZ}$ in $30 \mathrm{~mL}$ toluene and $23 \mu \mathrm{L}(32 \mathrm{mg}, 0.42 \mathrm{mmol})$ acetyl chloride was reacted. A catalytic amount of 3.5 mg DMAP were added. The mixture was stirred for $4 \mathrm{~h}$ to complete the reaction. Further procedure was performed as in case with the monoisocyanates.

Diisocyanates and equimolar amounts of ferrocenoylpiperazide with respect to the isocyanate functionalities were dissolved in anhydrous toluene, mixed with the dissolved isocyanate and stirred at room temperature for $30 \mathrm{~min}$. The solvent was removed by evaporation and orange solids were obtained. According to this procedure, the derivatives of toluene2,4-diisocyanate (2,4-TDI), toluene-2,6-diisocyanate (2,6-TDI), hexamethylene diisocyanate (HDI), diphenylmethane diisocyanate (MDI), and isophorone diisocyanate (IPDI) were synthesized.

\section{Characterization of the Synthesized Substances}

Ferrocenoyl piperazide. ${ }^{1} \mathrm{H}-\mathrm{NMR}(\delta / \mathrm{ppm}, 60 \mathrm{MHz}$, $\left.\mathrm{CDCl}_{3}\right): 1.73(\mathrm{~s}, 1 \mathrm{H}, \mathrm{NH}) ; 2.85(\mathrm{t}, 4 \mathrm{H}) ; 3.71(\mathrm{t}, 4 \mathrm{H}) ; 4.24(\mathrm{~s}$, $5 \mathrm{H}) ; 4.26(\mathrm{dd}, 2 \mathrm{H}) ; 4.54(\mathrm{dd}, 2 \mathrm{H}) ; \mathrm{IR}\left(\mathrm{cm}^{-1}, \mathrm{KBr}\right): 3306$ (m), $3074(\mathrm{w}), 3001(\mathrm{w}), 2974(\mathrm{w}), 2859(\mathrm{w}), 1617(\mathrm{~s}), 1540$ (s), $1470(\mathrm{~m}), 1410(\mathrm{~m}), 1285(\mathrm{~s}), 1263(\mathrm{w}), 1237(\mathrm{w}), 1173$ (w), $1006(\mathrm{~m}), 824(\mathrm{~m})$; ESI-MS (m/z): $299[\mathrm{M}+\mathrm{H}]^{+}$.

Fc-PZ-MIC. ${ }^{1} \mathrm{H}-\mathrm{NMR}\left(\delta / \mathrm{ppm}, 60 \mathrm{MHz}, \mathrm{CDCl}_{3}\right): 2.84$ $(\mathrm{d}, 2 \mathrm{H}) ; 3.49(\mathrm{~m}, 4 \mathrm{H}) ; 3.67(\mathrm{~m}, 4 \mathrm{H}) ; 4.23(\mathrm{~s}, 5 \mathrm{H}) ; 4.31(\mathrm{~m}$, 2H); $4.56(\mathrm{~m}, 2 \mathrm{H})$; IR ( $\left.\mathrm{cm}^{-1}, \mathrm{KBr}\right): 3366$ (m), 3083 (w), 2905 (w), 1608 (s), 1549 (s), 1470 (s), 1414 (s), 1262 (s), $1172(\mathrm{w}), 1147(\mathrm{w}), 1105(\mathrm{w}), 1001$ (m), $816(\mathrm{~m})$; ESI-MS $(\mathrm{m} / \mathrm{z}): 356[\mathrm{M}+\mathrm{H}]^{+}$.

Fc-PZ-EIC. ${ }^{1} \mathrm{H}-\mathrm{NMR}\left(\delta / \mathrm{ppm}, 60 \mathrm{MHz}, \mathrm{CDCl}_{3}\right): 1.15(\mathrm{t}$, $3 \mathrm{H}) ; 3.48(\mathrm{~m}, 6 \mathrm{H}) ; 3.67(\mathrm{~m}, 4 \mathrm{H}) ; 4.32$ (s, 5H); 4.41 (dd, 2H); 4.56 (dd, 2H); IR ( $\left.\mathrm{cm}^{-1}, \mathrm{KBr}\right): 3359$ (m), 3090 (w), 2975 (w), 2859 (w); 1616 (s), 1539 (s), 1470 (m), 1410 (m), 1265 (s), 1173 (w), 1141 (s), 1105 (w), 1006 (m), 824 (m); ESI-MS $(m / z): 370[\mathrm{M}+\mathrm{H}]^{+}$.

Fc-PZ-PIC. $\quad{ }^{1} \mathrm{H}-\mathrm{NMR}(\delta / \mathrm{ppm}, 60 \mathrm{MHz}, \mathrm{DMSO}): 3.54$ $(\mathrm{m}, 4 \mathrm{H}) ; 3.66(\mathrm{~m}, 4 \mathrm{H}) ; 4.27(\mathrm{~s}, 5 \mathrm{H}) ; 4.40(\mathrm{~m}, 2 \mathrm{H}) ; 4.60(\mathrm{~m}$, $2 \mathrm{H}) ; 7.26-7.44(\mathrm{~m}, 5 \mathrm{H})$; IR ( $\left.\mathrm{cm}^{-1}, \mathrm{KBr}\right): 3316(\mathrm{~m}), 3069$ (w), $2921(\mathrm{w}), 2856(\mathrm{w}), 1637$ (s), 1594 (s), 1537 (s), 1470 (w), 1444 (s) 1404 (w), 1244 (s), 1171 (w), 1147 (w), 1105 (w), 993 (m), $821(\mathrm{~m}), 754(\mathrm{~s})$; ESI-MS (m/z): $418[\mathrm{M}+\mathrm{H}]^{+}$.

Fc-PZ-MDI. ${ }^{1} \mathrm{H}-\mathrm{NMR}\left(\delta / \mathrm{ppm}, 60 \mathrm{MHz}, \mathrm{CDCl}_{3}\right): 3.52$ $(\mathrm{m}, 8 \mathrm{H}) ; 3.65(\mathrm{~m}, 8 \mathrm{H}) ; 3.84(\mathrm{~m}, 2 \mathrm{H}) ; 4.23(\mathrm{~s}, 10 \mathrm{H}) ; 4.34$ $(\mathrm{m}, 4 \mathrm{H}) ; 4.55(\mathrm{~m}, 4 \mathrm{H}) ; 6.88-7.21(\mathrm{~m}, 8 \mathrm{H})$; IR $\left(\mathrm{cm}^{-1}, \mathrm{KBr}\right)$ : 
$3433(\mathrm{~m}), 3097(\mathrm{w}), 2915(\mathrm{w}), 2853(\mathrm{w}) ; 1645(\mathrm{~s}), 1595(\mathrm{~s})$, 1513 (s), 1471 (s), 1413 (s), 1242 (s), 1172 (w), 1105 (w), 993 (m); 991 (w); $820(\mathrm{~m}) ; 728$ (m); ESI-MS (m/z): 847 [M $+\mathrm{H}]^{+}$.

Fc-PZ-IPDI. ${ }^{1} \mathrm{H}-\mathrm{NMR}\left(\delta / \mathrm{ppm}, 60 \mathrm{MHz}, \mathrm{CDCl}_{3}\right): 0.96-$ $1.10(\mathrm{~m}, 15 \mathrm{H}) ; 1.7(\mathrm{~m}, 1 \mathrm{H}) ; 3.46(\mathrm{~m}, 8 \mathrm{H}) ; 3.71(\mathrm{~m}, 8 \mathrm{H})$; $4.24(\mathrm{~s}, 10 \mathrm{H}) ; 4.33(\mathrm{~m}, 4 \mathrm{H}) ; 4.57(\mathrm{~m}, 4 \mathrm{H}) ; \mathrm{IR}\left(\mathrm{cm}^{-1}, \mathrm{KBr}\right)$ : 3355 (m), 3086 (w); 2900 (m); 1622 (s); 1538 (s); 1471 (s); 1410 (m); 1251 (s); 1171 (w); 1105 (w); 1003 (m); 821 (w); ESI-MS $(m / z): 819[\mathrm{M}+\mathrm{H}]^{+}$.

Fc-PZ-HDI. $\quad{ }^{1} \mathrm{H}-\mathrm{NMR}\left(\delta / \mathrm{ppm}, 60 \mathrm{MHz}, \mathrm{CDCl}_{3}\right): 1.01-$ $1.41(\mathrm{~m}, 8 \mathrm{H}) ; 3.34(\mathrm{~m}, 4 \mathrm{H}) ; 3.47(\mathrm{~m}, 8 \mathrm{H}) ; 3.68(\mathrm{~m}, 8 \mathrm{H})$; 4.25 (s, 10H); $4.34(\mathrm{~m}, 4 \mathrm{H}) ; 4.55(\mathrm{~m}, 4 \mathrm{H})$; IR $\left(\mathrm{cm}^{-1}, \mathrm{KBr}\right)$ : $3333(\mathrm{~m}), 3085$ (w), $2922(\mathrm{w}), 2856(\mathrm{w}), 1617$ (s), 1549 (s), 1465 (s), 1409 (s), 1254 (s), 1170 (m), 1105 (s), 823 (m); 757 (m); $731(\mathrm{~m})$; ESI-MS (m/z): $765[\mathrm{M}+\mathrm{H}]^{+}$.

Fc-PZ-2,4 TDI. ${ }^{1} \mathrm{H}-\mathrm{NMR}(\delta / \mathrm{ppm}, 60 \mathrm{MHz}, \mathrm{DMSO})$ : $2.02(\mathrm{~s}, 3 \mathrm{H}) ; 3.58(\mathrm{~m}, 8 \mathrm{H}) ; 3.68(\mathrm{~m}, 8 \mathrm{H}) ; 4.26(\mathrm{~s}, 10 \mathrm{H}) ; 4.39$ $(\mathrm{m}, 4 \mathrm{H}) ; 4.60(\mathrm{~m}, 4 \mathrm{H}) ; 7.05(\mathrm{~m}, 3 \mathrm{H})$; IR $\left(\mathrm{cm}^{-1}, \mathrm{KBr}\right): 3254$ (w), $3084(\mathrm{w}), 2909$ (w), $2855(\mathrm{w}), 1622$ (s), 1507 (s); 1471 (s), 1411 (s), 1249 (s), 1170 (m), 1105 (w), 1003 (m); 822 (w); $781(\mathrm{w}) ; 757(\mathrm{w}) ; \operatorname{ESI}-\mathrm{MS}(\mathrm{m} / \mathrm{z}): 771[\mathrm{M}+\mathrm{H}]^{+}$.

Fc-PZ-2,6 TDI. ${ }^{1} \mathrm{H}-\mathrm{NMR}(\delta / \mathrm{ppm}, 60 \mathrm{MHz}, \mathrm{DMSO})$ : $2.36(\mathrm{~s}, 3 \mathrm{H}) ; 3.53(\mathrm{~m}, 8 \mathrm{H}) ; 3.70(\mathrm{~m}, 8 \mathrm{H}) ; 4.26(\mathrm{~s}, 10 \mathrm{H}) ; 4.39$ $(\mathrm{m}, 4 \mathrm{H}) ; 4.57(\mathrm{~m}, 4 \mathrm{H}) ; 7.10(\mathrm{~m}, 3 \mathrm{H})$; IR $\left(\mathrm{cm}^{-1}, \mathrm{KBr}\right): 3324$ (w), 3095 (w), 2909 (w), 2857 (w), 1669 (s), 1646 (s), 1598 (s), 1516 (s), 1472 (s), 1416 (s), 1254 (s), 1174 (w), 1105 (w), 1003 (m); 819 (m); 760 (m); ESI-MS (m/z): $771[\mathrm{M}+$ $\mathrm{H}]^{+}$.

Fc-PZ-propyl isothiocyanate. ${ }^{1} \mathrm{H}-\mathrm{NMR} \quad(\delta / \mathrm{ppm}, 60$ $\left.\mathrm{MHz}, \mathrm{CDCl}_{3}\right): 0.98(\mathrm{t}, 3 \mathrm{H}) ; 1.75(\mathrm{~m}, 2 \mathrm{H}) ; 3.54-3.91(\mathrm{~m}$, $10 \mathrm{H}) ; 4.26(\mathrm{~s}, 5 \mathrm{H}) ; 4.36(\mathrm{~m}, 2 \mathrm{H}) ; 4.58(\mathrm{~m}, 2 \mathrm{H})$; IR $\left(\mathrm{cm}^{-1}\right.$, $\mathrm{KBr}): 3313$ (m), $3084(\mathrm{w}), 2955$ (w), $2922(\mathrm{w}) ; 2862(\mathrm{w})$, 1600 (s), 1542 (s), 1467 (s), 1411 (m), 1389 (m); 1348 (m); $1222(\mathrm{w}), 1105(\mathrm{w}), 1076(\mathrm{w}), 1008(\mathrm{~m}), 809(\mathrm{w}) ; 761(\mathrm{w})$; ESI-MS $(m / z): 400[\mathrm{M}+\mathrm{H}]^{+}$.

Acetyl-Fc-PZ. ${ }^{1} \mathrm{H}-\mathrm{NMR}\left(\delta / \mathrm{ppm}, 60 \mathrm{MHz}, \mathrm{CDCl}_{3}\right): 2.14$ $(\mathrm{s}, 3 \mathrm{H}) ; 3.69(\mathrm{~m}, 8 \mathrm{H}) ; 4.25$ (s, 5H); $4.35(\mathrm{dd}, 2 \mathrm{H}) ; 4.54(\mathrm{dd}$, 2H); IR ( $\left.\mathrm{cm}^{-1}, \mathrm{KBr}\right)$ : 3445 (m), 3073 (w), 2919 (w); 1626 (s), 1603 (s); 1451 (s), 1434 (s), 1360 (m), 1282 (m); 1282 (m); 1249 (s), 1171 (m), 1105 (w), 1002 (m), 862 (w); 816 (w); $\operatorname{ESI-MS~}(m / z): 341[\mathrm{M}+\mathrm{H}]^{+}$.
Air sampling was performed using a two-channel air sampler pump (Model 1067) from Supelco (Bellefonte, PA). Flow rates were determined using a DryCal DClite flow calibrator from Bios (Butler, NJ).

The generation of an isocyanate-containing atmosphere was performed in dry glassware to avoid hydrolysis of the reactive compounds. A $500 \mathrm{~mL}$ round bottom flask was partly filled with a commercially available MDI based PUR foam (E-Coll from E/D/E $\mathrm{GmbH}$, Wuppertal, Germany). After letting the foam harden and dry for $30 \mathrm{~min}$, the flask was connected to an impinger containing $24.3 \mathrm{mg}(0.08 \mathrm{mmol}) \mathrm{Fc}-\mathrm{PZ}$ in 50 $\mathrm{mL}$ of acetonitrile. Impingers are glass bubble tubes designed for the collection of airborne hazardous substances into a liquid medium. For $20 \mathrm{~min}$, the flask was heated with a Bunsen-type burner to decompose the PUR material. This procedure is simulating a process where heat is applied to PUR foams, such as welding of insulated water pipes. During this time period, air samples of $200 \mathrm{~mL} / \mathrm{min}$ were continuously taken from the flask and bubbled through the impinger.

\section{Results and Discussion}

Ferrocenoyl piperazide (Fc-PZ) was synthesized as a new derivatizing agent for the analysis of isocyanates following a two-step route, which is presented in Figure 1. The first step consisted of the reaction of the commercially available ferrocenecarboxylic acid to the respective ferrocenecarboxylic acid chloride (FCC) by using oxalyl chloride and catalytic amounts of N,Ndimethylaminopyridine. This procedure was introduced by Rolfes and Andersson [23, 24], but for this work, a slightly modified version by Karst et al. [40] was applied. FCC was then reacted with an excess of piperazine under formation of Fc-PZ. Despite the excess of piperazine, small amounts of bis(ferrocenoyl)piperazide are formed as side product. Therefore, purification of the reagent was carried out by preparative column liquid chromatography. The reagent was characterized by means of ${ }^{1} \mathrm{H}-\mathrm{NMR}$ and IR spectroscopy as well as electrospray mass spectrometry (ESI-MS). The respective data are listed in the Experimental Section.

For calibration purposes, a series of isocyanate derivatives was synthesized according to Figure 2. The reaction between equimolar amounts of Fc-PZ and isocyanates rapidly yielded the desired products, which were characterized as in case of the reagent. The deriv-

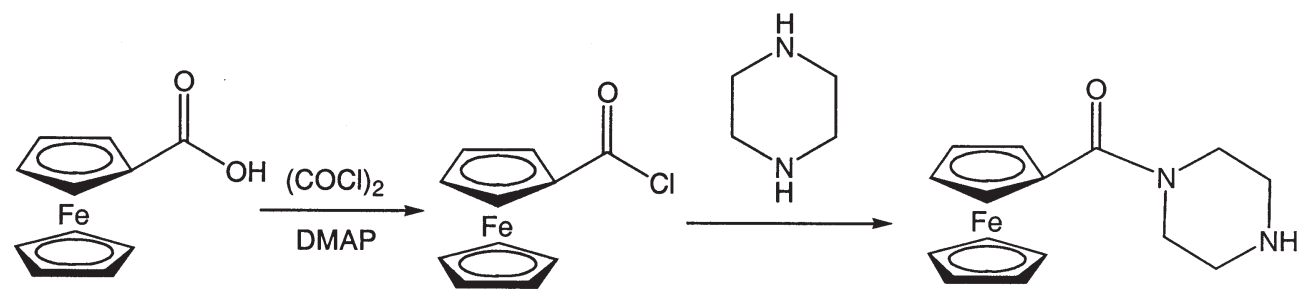

Figure 1. Synthesis of Fc-PZ. 


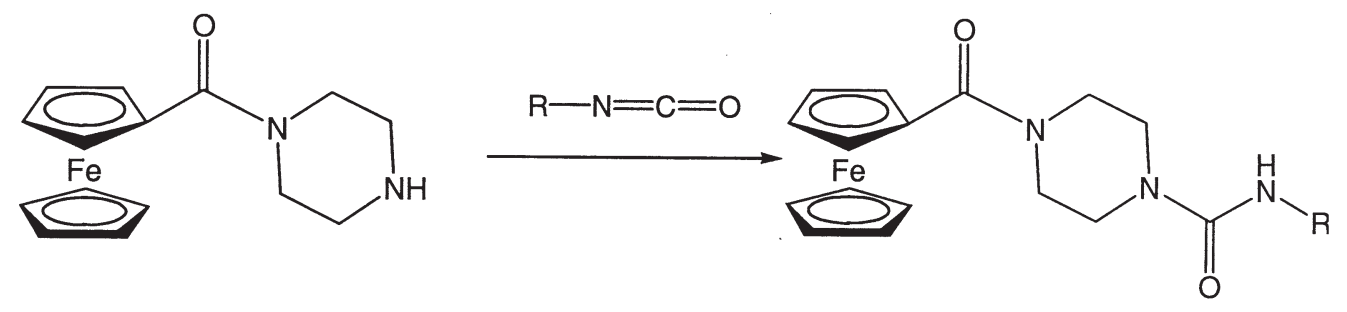

Figure 2. Synthesis of the isocyanate derivatives of Fc-PZ.

atives of methyl isocyanate (MIC), ethyl isocyanate (EIC), phenyl isocyanate (PIC), methylenebis $\left(4,4^{\prime}\right.$-phenylisocyanate) (MDI), isophorone diisocyanate (IPDI), hexamethylene diisocyanate (HDI), and the 2,4- and 2,6-isomers of toluylene diisocyanate (2,4-TDI and 2,6TDI) were obtained this way.

The chromatographic separation of the derivatives was optimized as follows. For the planned electrochemical conversion of the derivatives after separation, it is important to use a conductive mobile phase, which contains volatile buffers. From earlier work on the analysis of ferrocene-derivatized alcohols and phenols, it was known that a binary gradient consisting of acetonitrile and an aqueous formic acid/ammonium formate buffer with $\mathrm{pH} 3$ fulfills these requirements [40-42]. Initial tests confirmed that this mobile phase is also suitable for the separation of the derivatized isocyanates. Various stationary phases were tested, and it became evident that the separation of the derivatives of the aliphatic isocyanates can easily be performed on different reversed-phase columns. However, the separation of the two TDI derivatives and the HDI derivative was difficult, as was reported earlier for the separation of NBDPZ-derivatives of these isocyanates [18]. As in this case, a phenyl-modified stationary phase proved to be better suited for the baseline separation of all three derivatives than $\mathrm{C}_{18}$-modified columns. The chromatogram of a standard mixture consisting of the derivatives of MIC, EIC, PhIC, IPDI, 2,4-TDI, HDI, 2,6-TDI, and MDI using UV/vis and electrochemistry/MS detection is provided in Figure 3. The optimization of the electrochemistry/MS detection is described in detail below. When comparing the relative signal intensities in UV/vis and MS detection, it becomes evident that in most cases, a good correlation is obtained. However, for the derivatives of the aromatic isocyanates (2,4-TDI, 2,6-TDI, and MDI), the relative intensity of the UV absorbance signal is larger due to the strong absorbance of the aromatic rings at the detection wavelength. The chromatogram proves that all of the investigated derivatives can be well separated under the selected conditions. The derivative of HDI elutes between the two TDI isomers. For IPDI, two structural isomers are observed at slightly different retention times. With this separation, the analysis of real samples should be possible. This was investigated in detail as described later in this article.

When analyzing the derivatives with LC/ESI-MS or
LC/APCI-MS, but without electrochemical pretreatment in the positive ion mode, the $[\mathrm{M}+\mathrm{H}]^{+}$pseudomolecular ions were observed in all cases. Signal intensities were poor due to the limited polarity of the analytes. For electrochemistry/MS measurements, a porous glassy carbon cell with a very large surface area was used with the goal to obtain a high conversion rate of the ferrocene derivatives. This electrochemical cell uses $\mathrm{Pd}$ as the counter electrode, and a $\mathrm{Pd} / \mathrm{H}_{2}$ reference system. All potentials provided for the on-line conversion were determined against this reference electrode, with the mobile phase used for the LC separations (see above). The commercial APCI interface was used without any technical modifications, but with the corona voltage switched to only $0.1 \mathrm{kV}$, in the "heated nebulizer" or "thermospray" mode. This allows improving the selectivity, as no further unselective ionization process increases the background signal.

The mass spectra for selected derivatives using LC/ electrochemistry/MS under these conditions were recorded in the following. Figure 4 shows the mass spectrum of the EIC derivative, the structure of which is inserted. Due to the electrochemical conversion, the ferrocinium ion is formed, which leads to the $[\mathrm{M}]^{+}$ signal as base peak. Compared with the approach without electrochemical conversion, signal intensities are much higher, typically by a factor of 50 . Under these conditions, the $[\mathrm{M}+\mathrm{H}]^{+}$ion does not contribute significantly to the signal. The inserted mass spectrum shows the calculated abundance of the masses under consideration of the isotopic pattern of the elements. This correlates well with the measured isotopic pattern.

For all derivatives of the diisocyanates, $[\mathrm{M}]^{2+}$ ions are predominant, while $[\mathrm{M}]^{+}$ions are not detected at all. The mass spectrum of the IPDI derivative and its chemical structure are shown in Figure 5. The dual charge of the derivative is proven by the isotopic pattern of the peak (not shown). Obviously, both ferrocene groups are oxidized during this experiment, as no peak is observed for the singly charged oxidation product at $m / z=818$. This is marked by an arrow in Figure 5.

To study the electrochemical behavior of the ferrocenoyl piperazides, cyclic voltammetry is performed in a mixture of acetonitrile and ammonium formate buffer. The redox system shows a reversible one-electron oxidation of the ferrocene derivative to the ferrocinium cation (Figure 6). The half-wave potential for the deri- 


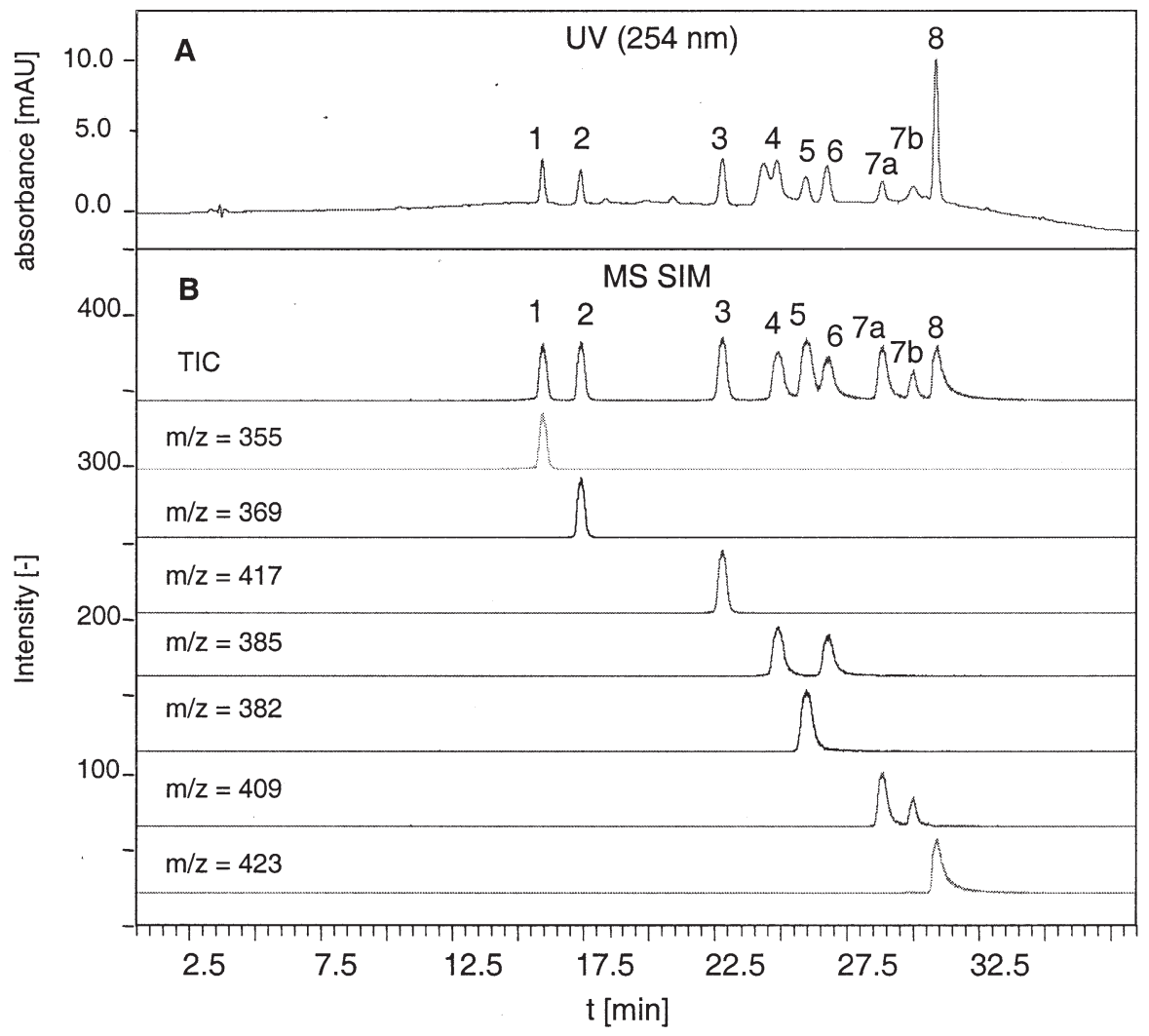

Figure 3. Separation of a mixture of Fc-PZ isocyanate derivatives, concentrations between $1.4^{*} 10^{-5}$ and $2.0^{*} 10^{-5} \mathrm{M}$ for monoisocyanate derivatives and between $8.0^{*} 10^{6}$ and $9.2^{*} 10^{-6} \mathrm{M}$ for the derivatives of diisocyanates. Peak assignment: Fc-PZ-MIC (1), Fc-PZ-EIC (2), Fc-PZ-PIC (3), Fc-PZ-2, 6 TDI (4), Fc-PZ-HDI (5), Fc-PZ-2, 4 TDI (6), Fc-PZ-IPDI (7 a,b), Fc-PZ-MDI (8). (a) UV chromatogram recorded at $254 \mathrm{~nm}$; (b) MS chromatogram, selected ion monitoring (SIM) mode, potential of the electrochemical flow cell $0.5 \mathrm{~V}$ versus $\mathrm{Pd} / \mathrm{H}_{2}$.

vatization reagent is found to be $480 \mathrm{mV}$ vs. $\mathrm{Ag} / \mathrm{AgCl}$. As expected, the influence of the individual isocyanate derivatives was neglectable and the potentials were found to be in the same range.

The dependency of the obtained signal on the ap-

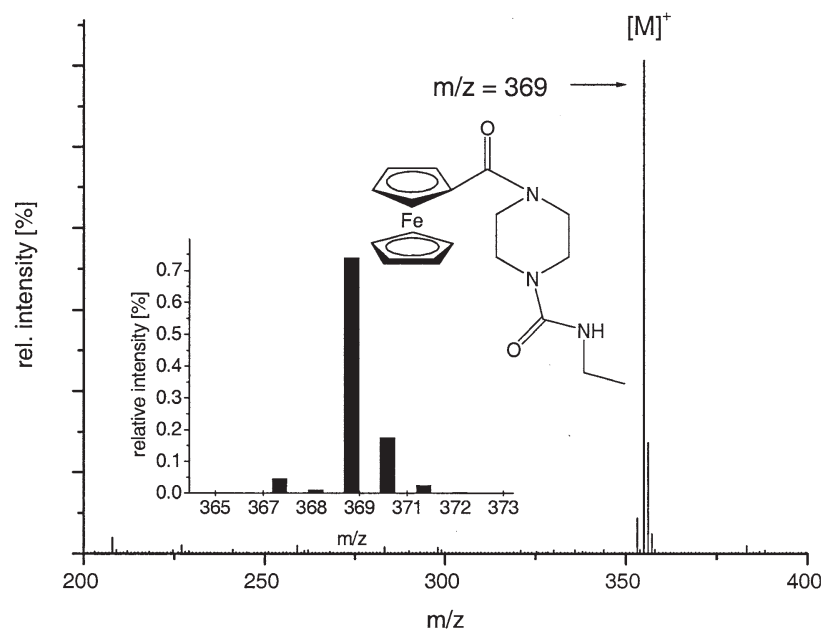

Figure 4. Mass spectrum of Fc-PZ-EIC obtained with electrochemical oxidation. Inserted are the chemical structure of the analyte as well as the calculated isotopic pattern. plied potential is presented in Figure 7. Small signals are obtained for the monoisocyanates at a potential of $0.3 \mathrm{~V}$ versus $\mathrm{Pd} / \mathrm{H}_{2}$, while the diisocyanates are not detected at all under these conditions. The highest signals for all compounds were observed at $0.5 \mathrm{~V}$, and

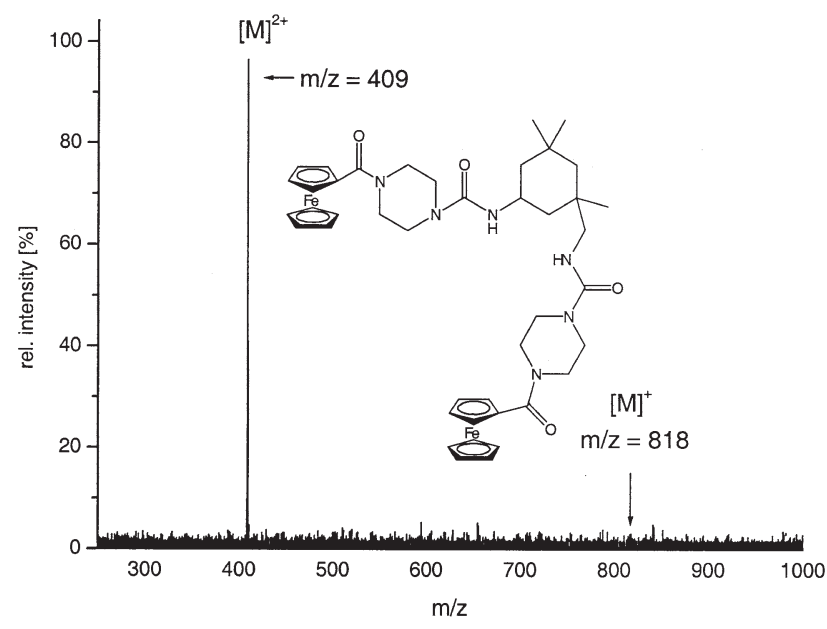

Figure 5. Mass spectrum of Fc-PZ-IPDI obtained with electrochemical oxidation. Inserted is the chemical structure of the analyte. 


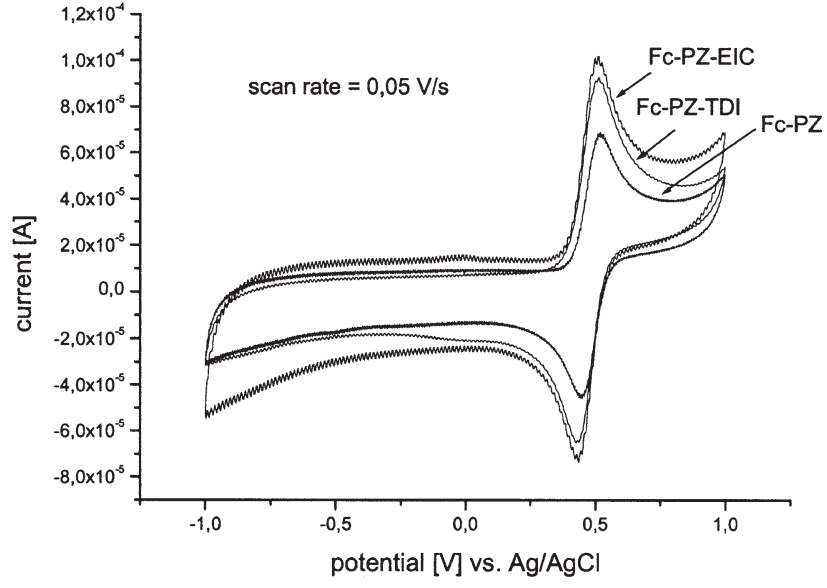

Figure 6. Cyclic voltammogram of Fc-Pz (0.35 mM), Fc-PZ-EIC $(0.37 \mathrm{mM})$, and Fc-PZ-2.6 TDI $(0.32 \mathrm{mM})$ in an 1:1 mixture of acteonitrile and ammonium formate buffer.

this potential was therefore selected for all further measurements. In the range up to $0.7 \mathrm{~V}$, only a minor decrease of the signal is observed for all derivatives. With further increase of the potential, however, the derivatives of aromatic isocyanates rapidly lose signal intensity, while the derivatives of the aliphatic isocyanates (MIC, EIC, and to a lesser extent, HDI and IPDI), still can be detected at $1.0 \mathrm{~V}$. This indicates that the aromatic ring is involved in further oxidation processes of the derivatives.

The analytical figures of merit were determined for these derivatives. The respective data are listed in Table 1. Limits of detection range from 6 to $20 \mathrm{nmol} / \mathrm{L}$, limits of quantification from 20 to $50 \mathrm{nmol} / \mathrm{L}$. The linear ranges extend over two decades for all derivatives.

To investigate the suitability of the reagent for the analysis of real samples, the thermal degradation of an MDI-based polyurethane foam was studied. It is known from literature that, besides the isocyanate which was
Table 1.

\begin{tabular}{lccc}
\hline Analyte & $\begin{array}{c}\text { LOD } \\
{[\mathrm{nM}]}\end{array}$ & $\begin{array}{c}\text { LOQ } \\
{[\mathrm{nM}]}\end{array}$ & $\begin{array}{c}\text { RSD } \\
(\mathrm{n}=3 ; \mathrm{c}=0.2 \mu \mathrm{M})\end{array}$ \\
\hline \hline Fc-PZ-MIC & 20 & 60 & $2.2 \%$ \\
Fc-PZ-EIC & 16 & 50 & $4.0 \%$ \\
Fc-PZ-PIC & 13 & 40 & $1.1 \%$ \\
Fc-PZ-2,6 TDI & 7 & 20 & $5.9 \%$ \\
Fc-PZ-HDI & 12 & 40 & $2.1 \%$ \\
Fc-PZ-2,4 TDI & 10 & 30 & $4.5 \%$ \\
Fc-PZ-IPDI & 13 & 40 & $4.3 \%$ \\
Fc-PZ-MDI & 6 & 20 & $7.1 \%$ \\
\hline
\end{tabular}

used for synthesizing the polymer, smaller isocyanates may be observed during this procedure [43]. This simulates a welding process at a metal pipe, which is insulated with polyurethane material. Sampling was performed with an impinger, which was filled with 50 $\mathrm{mL}$ of a $1.6 \mathrm{mM}$ solution of Fc-PZ in acetonitrile. The air samples were pumped through the impinger at a flow rate of $300 \mathrm{~mL} / \mathrm{min}$. Initial experiments with known amounts of nebulized isocyanates proved that the recovery was quantitative under these conditions. In Figure 8, the results of the mass spectrometric analysis of the sampling impinger are presented. As a very large amount of MDI was released, the sample was diluted for the determination of MDI by a factor of 1000 prior to injection into the LC/MS system. It should be noted that some peak tailing is obtained for MDI in this experiment. It is assumed that this is due to absorption or precipitation of the derivative on the cell material and subsequent slow release by oxidation at these high concentrations. This effect was only observed for very high concentrations of those derivatives with the lowest polarity. PIC was found in very high concentrations as well. As was expected from literature data [43], isocyanic acid (ICA), MIC, EIC, and propyl isocyanate are all detected as degradation side-products at low concentrations in the undiluted impinger solution. However,

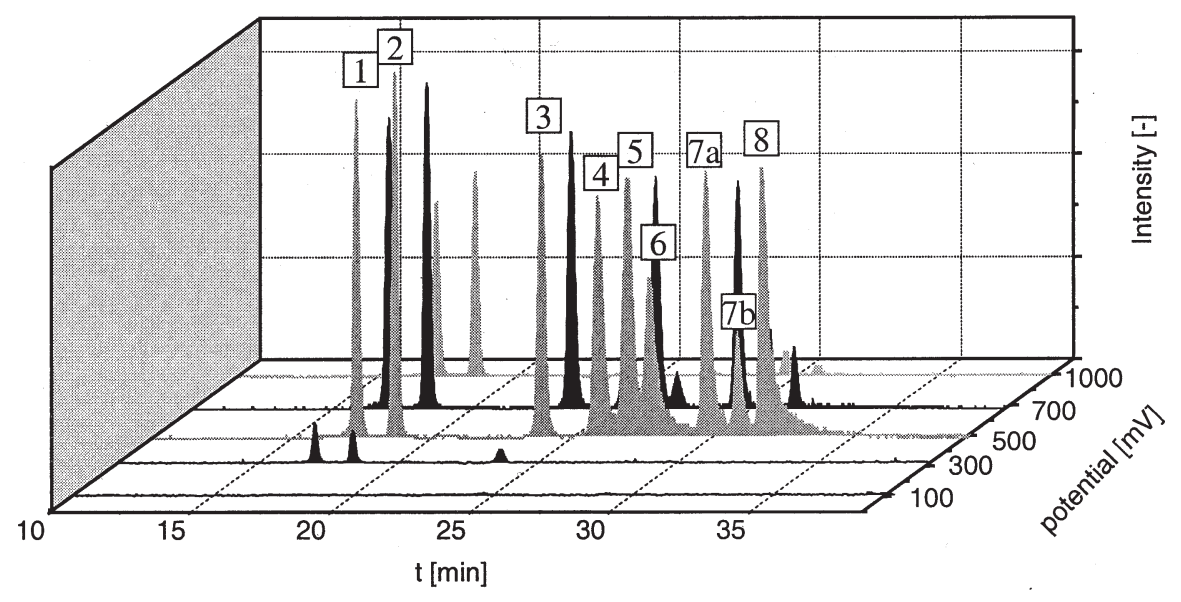

Figure 7. Dependency of the signal intensity on the applied electrochemical potential varied between 0.1 to $1.0 \mathrm{~V}$ versus $\mathrm{Pd} / \mathrm{H}_{2}$, selected ion monitoring (SIM) mode, peak assignment: Fc-PZ-MIC (1), Fc-PZ-EIC (2), Fc-PZ-PIC (3), Fc-PZ-2,6-TDI (4), Fc-PZ-HDI (5), Fc-PZ-2,4-TDI (6), Fc-PZ-IPDI (7 a,b), FC-PZ-MDI (8). 


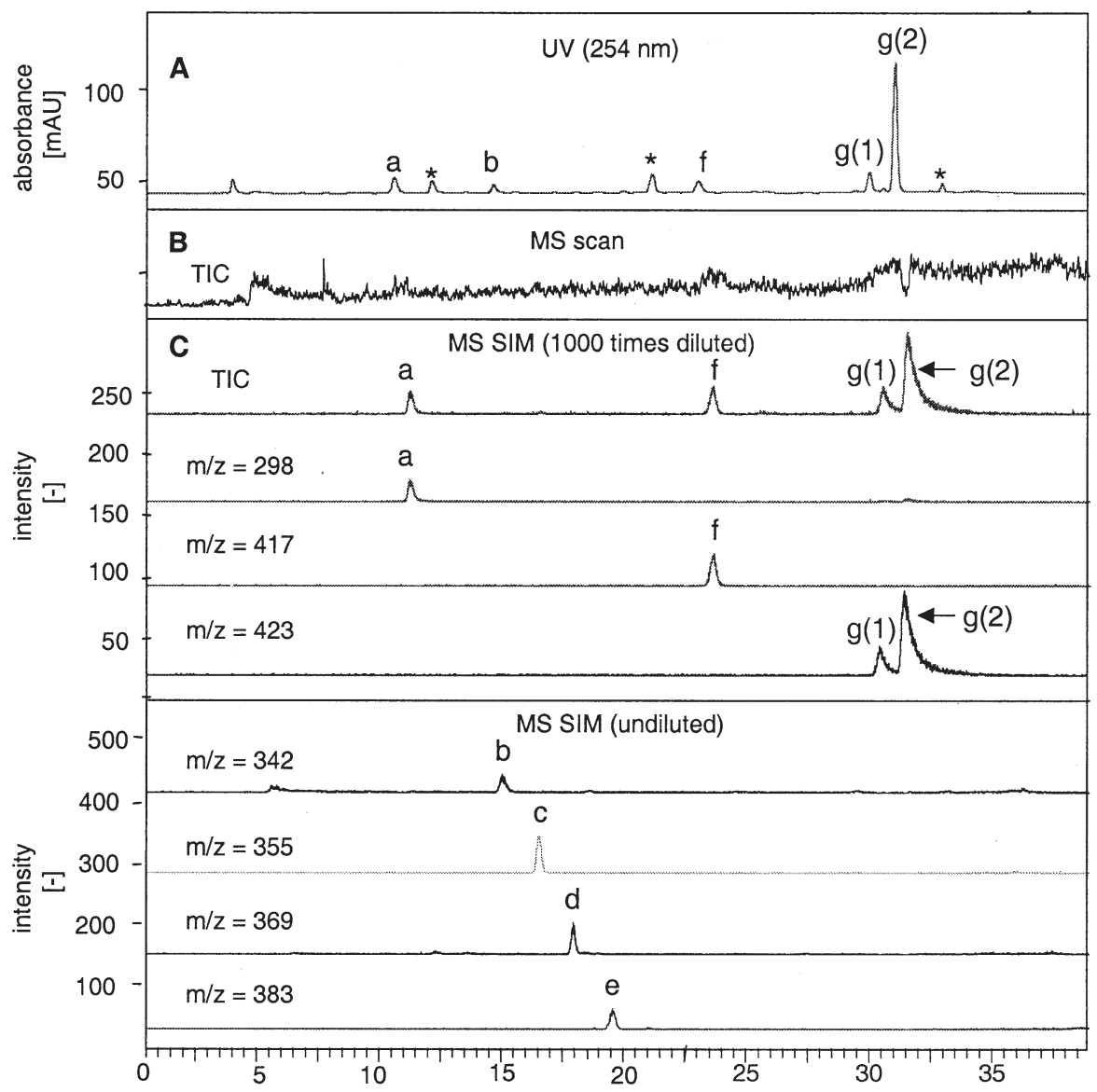

Figure 8. Chromatogram of a thermally treated PUR sample. Peak assignment: Fc-PZ (a), Fc-PZ-ICA (b), Fc-PZ-MIC (c), Fc-PZ-EIC (d), Fc-PZ-PrIC (e), Fc-PZ-PIC (e), Fc-PZ-MDI (g[1], g[2]). (a) UV chromatogram recorded at $254 \mathrm{~nm}$; (b) MS chromatogram scan mode $\mathrm{m} / \mathrm{z}=200-2000$; (c) MS chromatogram, selected ion monitoring (SIM) mode, electrochemical flow cell $0.5 \mathrm{~V}$ versus $\mathrm{Pd} / \mathrm{H}_{2}$. The asterisks indicate unidentified compounds, which occured in the UV trace, but which could not be detected by mass spectrometry.

the selected sampling arrangement does not allow a quantitative evaluation of these data. The asterisks indicate unidentified compounds which occured in the UV trace, but which could not be detected by mass spectrometry under the conditions used for this work. Therefore, it can be assumed that these peaks are not isocyanate derivatives.

It is obvious that a piperazine function is, in principle, also capable of reacting with isothiocyanates or acid chlorides. To investigate the possibility to apply Fc-PZ for this purpose as well, the respective derivatives of propyl isothiocyanate and acetyl chloride were synthesized and characterized (see above). The mass spectrum of the propyl isothiocyanate derivative of Fc-PZ after electrochemical oxidation is presented in Figure 9, which includes an insert of the calculated isotopic pattern and the chemical structure of the derivative. Again, the $[\mathrm{M}]^{+}$peak is predominant, but the $[\mathrm{M}]^{+}$of the reagent itself is observed as fragment at $\mathrm{m} / \mathrm{z}=298$. The mass spectrum of the Fc-PZ derivative of acetyl chloride after electrochemical oxidation is presented in

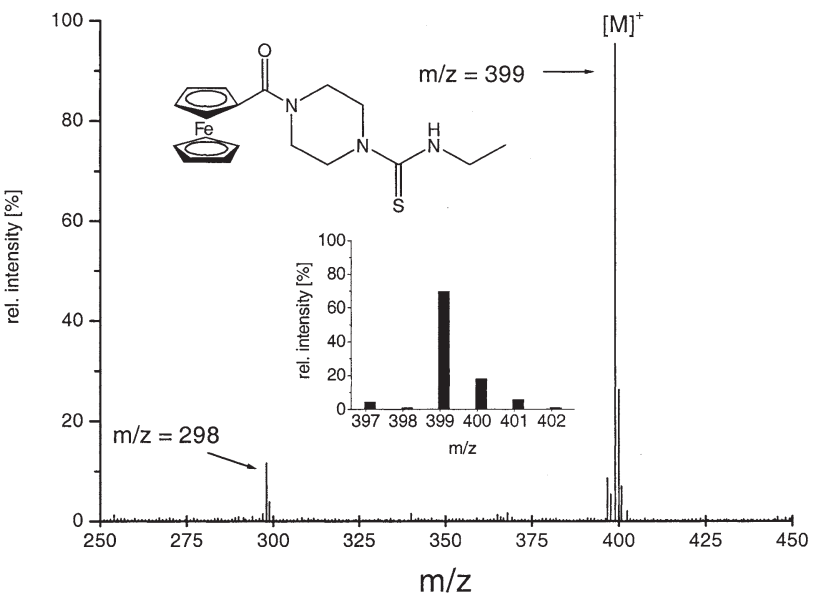

Figure 9. Mass spectrum of Fc-PZ-propyl isothiocyanate obtained with electrochemical oxidation. Inserted are the chemical structure of the analyte and the calculated isotopic pattern. 


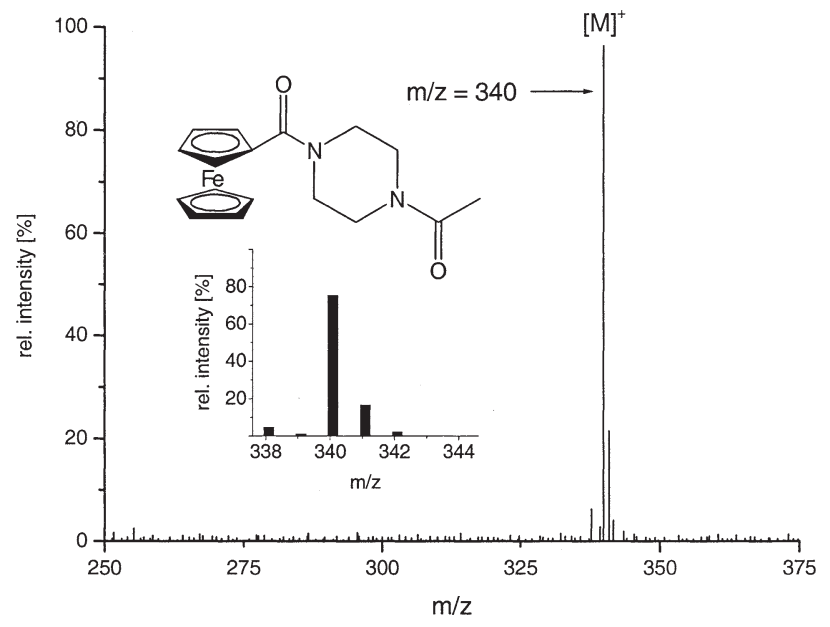

Figure 10. Mass spectrum of acetyl Fc-PZ obtained with electrochemical oxidation. Inserted are the chemical structure of the analyte as well as the calculated isotopic pattern.

Figure 10, with the inserted chemical structure and calculated isotopic pattern. As in the previous cases, the $[\mathrm{M}]^{+}$peak dominates. As in case of the isocyanate derivatives, but in contrast to the isothiocyanate derivative, no fragmentation is observed. It is therefore evident that the reagent is, in principle, suitable to be used for the analysis of this group of compounds as well. These findings are also important to evaluate possible interferences in the analysis of isocyanates in real samples using related reagents, which were mostly carried out with LC and UV/vis detection in previous times. In this case, misinterpretations of unknown peaks in the chromatograms as isocyanates are possible. The use of LC/MS is therefore strongly recommended to increase selectivity.

\section{Conclusions}

Fc-PZ has been introduced as promising new reagent for the analysis of isocyanates and, possibly, isothiocyanates and carboxylic acid chlorides by LC/electrochemistry/MS. Detection limits are good, considering the LC/MS instrument that was used. Future work should be directed to the development of more suitable air sampling devices, e.g., reagent-coated test tubes and/or passive sampling devices. Furthermore, the use of tandem mass spectrometry should significantly improve the limits of detection and the selectivity of the method. Fragmentation experiments of the doubly charged diisocyanate derivatives could lead to a very high selectivity because of the possible formation of singly charged fragments with higher $\mathrm{m} / \mathrm{z}$ ratio than the parent compound. In future work, the application of the described method to the analysis of isocyanates in liquid samples should be tested. It seems to be promising that polyurethane prepolymers and related compounds with a larger number of isocyanate functionalities could react with several Fc-PZ molecules, and could thus possibly be multiply charged after electrochemical oxidation. This might allow to analyze (pre)polymers of comparably high masses in combination with highresolution mass spectrometry, e.g., with a TOF instrument.

\section{Acknowledgments}

The authors gratefully acknowledge financial support by the Nederlandse Organisatie voor Wetenschappelijk Onderzoek (NWO, Den Haag, The Netherlands) and the Fonds der Chemischen Industrie (Frankfurt am Main, Germany).

\section{References}

1. Ulrich, H. Chemistry and Technology of Isocyanates; John Wiley and Sons: Chichester, New York, Brisbane, Toronto, Singapore, 1996.

2. Purnell, C. J.; Walker, R. F. Methods for the determination of atmospheric organic isocyanates. A review. Analyst 1985, 110, 893-905.

3. Elms, J.; Beckett, P. N.; Griffin P.; Curran, A. D. Mechanisms of isocyanate sensitization. An in vitro approach. Toxicol. in Vitro 2001, 15, 631-634.

4. Karlsson, D.; Dahlin, J.; Skarping, G.; Dalene, M. Determination of isocyanates, aminoisocyanates, and amines in air formed during the thermal degradation of polyurethane. J. Environ. Monit. 2002, 4, 216-222.

5. Karlsson, D.; Spanne, M.; Dalene, M.; Skarping, G. Airborne thermal degradation products of polyurethane coatings in car repair shops. J. Environ. Monit. 2000, 2, 462-469.

6. Marcali, K. Microdetermination of toluenediisocyanates in atmosphere. Anal. Chem. 1957, 29, 552-558.

7. Warwick, C. J.; Bagon, D. A.; Purnell, C. J. Application of electrochemical detection to the measurement of free monomeric aromatic and aliphatic isocyanates in air by highperformance liquid chromatography. Analyst 1981, 106(6), 676-685.

8. Kääriä, K.; Hirvonen, A.; Norppa, H.; Piirilä, P.; Vainio, H.; Rosenberg, C. Exposure to 4,4'-methylenediphenyl diisocyanate (MDI) during molding of rigid polyurethane foam: Determination of airborne MDI and urinary $4,4^{\prime}$-methylenedianiline (MDA). Analyst 2001, 126, 476-479.

9. Molander, P.; Haugland, K.; Fladseth, G.; Lundanes, E.; Thorud, S.; Thomassen, Y.; Greibrokk, T. Determination of 1-(2methoxyphenyl)piperazine derivatives of isocyanates at low concentrations by temperature-programmed miniaturized liquid chromatography. J. Chromatogr. A 2000, 892, 67-74.

10. Ekman, J.; Levin, J. O.; Lindahl, R.; Sundgren, M.; Östin, A. Comparison of sampling methods for 1,6-hexamethylene diisocyanate, (HDI) in a commercial spray box. Analyst 2002, $127,169-173$.

11. Methods for the determination of hazardous substances, MDHS 25/3: Organic isocyanates in air; Health and Safety Executive (HSE): London, 1999.

12. Henriks-Eckerman, M.-L.; Välimaa, J.; Rosenberg, C. Determination of airborne methyl isocyanate as dibutylamine or 1-(2-methoxyphenyl)piperazine derivatives by liquid and gas chromatography. Analyst 2000, 125, 1949-1954.

13. Sangö C.; Zimerson, E. A new reagent for determination of isocyanates in working atmospheres by HPLC using UV or fluorescence detection. J. Liq. Chromatogr. 1980, 2, 971-990.

14. Andersson, K.; Gudéhn, A.; Hallgren, C.; Levin, J. O.; Nilsson, C.-A. Monitoring 1,6-hexamethylene diisocyanate in air by chemosorption sampling. Scand. J. Work Environ. Health 1983, 9, 497-503. 
15. Rudzinski, W. E.; Yin, J.; Norman, S. H.; Glaska, D. A. Determination of hexamethylene-based isocyanates in spraypainting operations. Part 1. Evaluation of a polyurethane foam sponge sampler. Analyst 1998, 123, 2079-2083.

16. Streicher, R. P.; Arnold, J. E.; Ernst, M. K.; Cooper, C. Development of a novel derivatization reagents for the sampling and analysis of total isocyanate group in air and comparison of its performance with that of several established reagents. Am. Ind. Hyg. Asoc. J. 1996, 57, 905-913.

17. OSHA Analytical Laboratory, Method No. 54: Methyl Isocyanate (MIC); OSHA: Salt Lake City, 1985.

18. Vogel, M.; Karst, U. 4-Nitro-7-piperazino-2,1,3-benzoxadiazole as a reagent for monitoring of airborne isocyanates by liquid chromatography. Anal. Chem. 2002, 74, 6418-6426.

19. Karlsson, D.; Dalene, M.; Skarping, G. Determination of complex mixtures of airborne isocyanates and amines. Part 5. Determination of low molecular weight aliphatic isocyanates as dibutylamine derivatives. Analyst 1998, 123, 1507-1512.

20. Henneken, H.; Lindahl, R.; Östin, A.; Vogel, M.; Levin, J. O.; Karst, U. Diffusive sampling of methyl isocyanate using 4-nitro-7-piperazinobenzo-2-oxa-1,3-diazole (NBDPZ) as derivatizing agent. J. Environ. Monit. 2003, 5, 100-105.

21. von Zweigbergk, P.; Lindahl, R.; Östin, A.; Ekman. J.; Levin, J. O. Development of a diffusive sampling method for determination of methyl isocyanate in air. J. Environ. Monit. 2002, 4, 663-666.

22. Brooks, C. J. W.; Cole, W. J. Cyclic ferroceneboronates as derivatives for the gas chromatographic separation and characterization of diols and related compounds. J. Chromatogr. 1987, 399, 207-221.

23. Rolfes, J.; Andersson, J. T. Determination of trace amounts of alcohols and phenols in complex mixtures as ferrocenecarboxylic acid esters with gas chromatography-atomic emission detection. Anal. Commun. 1996, 33, 429-433.

24. Rolfes, J.; Andersson, J. T. Determination of Alkylphenols after derivatization to ferrocenecarboxylic acid esters with gas chromatography-atomic emission detection. Anal. Chem. 2001, 73, 3073-3082.

25. Shimada, K.; Oe, T.; Nambara, T. Sensitive ferrocene reagents for derivatization of thiol compounds in high-performance liquid chromatography with dual-electrode Coulometric detection. J. Chromatogr. Biomed. Appl. 1987, 419, 17-25.

26. Shimada, K.; Sakayori, C.; Nambara, T. Determination of fatty acids by high-performance liquid chromatography with electrochemical detection using a ferrocene derivatization reagent. J. Liq. Chromatogr. 1987, 10, 2177-2187.

27. Gamoh, K.; Sawamoto, H.; Kakatsuto, S.; Watabe, Y.; Arimoto, $\mathrm{H}$. Ferroceneboronic acid as a derivatization reagent for the determination of brassinosteroids by high-performance liquid chromatography with electrochemical detection. J. Chromatogr. 1990, 515, 227-231.

28. Eckert, H.; Koller, M. Derivatization reagents based on ferrocene for HPLC-ECD determination of peptides and proteins. J. Liq. Chromatogr. 1990, 13, 3399-3414.

29. Eckert, H.; Koller, M. Derivatisierungsreagenzien für die HPLC-ECD-Analyse von Peptiden und Proteinen auf Ferrocenbasis: Synthese und Umsetzung mit H-Phe-OtBU als Eignungstest. Z. Naturforsch. 1990, 45b, 1709-1714.
30. Cox, R. L.; Schneider, T. W.; Koppang, M. D. Ferrocene tagging of amines, amino acids, and peptides for liquid chromatography with electrochemical detection. Anal. Chim. Acta 1992, 262, 145-159.

31. Shimada, K.; Kawai, Y.; Oe, T.; Nambara, T. Determination of amino acids by high performance liquid chromatography with electrochemical detection using ferrocene derivatization reagents. J. Liq. Chromatogr. 1989, 12, 359-371.

32. Shimada, K.; Oe, T.; Tanaka, M.; Nambara, T. Sensitive ferrocene reagents for derivatization of amines for high-performance liquid chromatography with electrochemical detection. J. Chromatogr. Biomed. Appl. 1989, 487, 247-255.

33. Lo, K. K.-W.; Ng, D. C.-M.; Lau, J. S.-Y.; Wu, R. S.-S.; Lam, P. K.-S. Derivatization of microcystin with a redox-active label for high-performance liquid chromatography/electrochemical detection. New J. Chem. 2003, 27, 274-279.

34. Van Berkel, G. J.; Quirke, J. M. E.; Tigani, R. A.; Dilley, A. S.; Covey, T. R. Derivatization for electrospray ionization mass spectrometry. 3. Electrochemically ionizable derivatives. Anal. Chem. 1998, 70, 1544-1554.

35. Quirke, J. M. E.; Hsu, Y.-L.; Van Berkel, G. J. Ferrocene-based electroactive derivatizing reagents for the rapid selective screening of alcohols and phenols in natural product mixtures using electrospray-tandem mass spectrometry. J. Nat. Prod. 2000, 63, 230-237.

36. Quirke, J. M. E.; Van Berkel, G. J. Electrospray tandem mass spectrometric study of ferrocene carbamate ester derivatives of saturated primary, secondary, and tertiary alcohols. J. Mass Spectrom. 2001, 36, 179-187.

37. Van Berkel, G. J.; Quirke, J. M. E.; Adams, C. L. Derivatization for electrospray ionization-mass spectrometry. 4. Alkenes and alkynes. Rapid Commun. Mass Spectrom. 2000, 14, 849-858.

38. Williams, D.; Young, M. K. Analysis of neutral isomeric low molecular weight carbohydrates using ferrocenyl boronate derivatization and tandem electrospray mass spectrometry. Rapid Commun. Mass Spectrom. 2000, 14, 2083-2091.

39. Williams, D.; Chen, S.; Young, M. K. Ratiometric analysis of the ferrocene boronate esters of 2- and 4-hydroxyestradiol by tandem electrospray mass spectrometry. Rapid Commun. Mass Spectrom. 2001, 15, 182-186.

40. Diehl, G.; Liesener, A.; Karst, U. Liquid chromatography with post-column electrochemical treatment and mass spectrometric detection of nonpolar compounds. Analyst 2001, 126, 288 290.

41. Diehl, G.; Karst, U. Fast liquid chromatography-electrochemistry-mass spectrometry of ferrocenecarboxylic acid esters. J. Chromatogr. A 2002, 974, 103-109.

42. Diehl, G.; Wasinski, F. A. H.; Roberz, B.; Luftmann, H.; Schmidt, T. C.; Andersson, J. T.; Karst, U. Liquid Chromatography/Electrochemistry/Mass Spectrometry as screening technique for alcohols and phenols in fuels. Microchim. Acta 2004, 146, 137-147.

43. Blomqvist, P.; Hertzberg, T.; Dalene, M.; Skarping, G. Isocyanates, aminoisocyanates, and amines from fires-a screening of common materials found in buildings. Fire Mater. 2003, 27, 275-294 